latent heat to the air parcel), and after eventually being compressed adiabatically to the standard pressure of 1000 mbar. As this process cannot alter $\theta_{\mathrm{e}}$, although vertical motion and a water-phase conversion take place, it is conserved for airmasses undergoing purely dryand moist-adiabatic processes. Real airflows do not strictly meet this restriction when precipitation is formed and falls out. Nevertheless, $\theta_{\mathrm{e}}$ is well suited to distinguish between airmasses from different temperature and moisture regimes. Large horizontal gradients in $\theta_{\mathrm{e}}$ are good indicators of frontal zones. Formulae to compute $\theta$ and $\theta_{\mathrm{e}}$ can be found in standard textbooks (e.g. Wallace and Hobbs 1977, p. 69 and p. 79).

\section{References}

Atkinson, B. W. and Gadd, A. (1986) Weather - a modern guide to forecasting. Mitchell Beazley, London, $160 \mathrm{pp}$.

Binder, P. and Schär, C. (1995) (Eds.) Mesoscale Alpine Programme - Design Proposal. SMA Zürich, 63pp. (can be obtained from SMA, CH-8044 Zürich, Switzerland)
Cullen, M. J. P. (1993) The unified forecast/climate model. Meteorol. Mag., 122, pp. 81-94

Egger, J. and Hoinka, K.-P. (1992) Fronts and orography. Meteorol. Atmos. Phys., 48, pp. 3-36

Heimann, D. (1990) Three-dimensional modeling of synthetic cold fronts approaching the Alps. Meteorol. Atmos. Phys., 42, pp. 197-219

Kurz, M. (1994) Die Kaltfront vom 10.2.1991 - Betrachtungen zur Erscheinungsform und zur Vorhersage orographisch beeinflußter Fronten. Meteorol. Z., Neute Folge, 3, pp. 275-287

Sherwood, J. (1995) The Papal front. Part 1: A forecaster's perspective. Weather, 50, pp. 98-106

Simmons, A. (1991) Development of a high resolution, semi-Lagrangian version of the ECMWF forecast model. In: Proceedings ECMWF Seminar on Numerical Methods in Atmospheric Models, Vol. II, Reading, pp. 281-324

Thorpe, A. J. and Clough, S. A. (1991) Mesoscale dynamics of cold fronts: Structures described by dropsoundings in FroNTs 87. Q. F. R. Meteorol. Soc., 117, pp. 903-941

Volkert, H., Weickmann, L. and Tafferner, A. (1991) The Papal Front of 3 May 1987: A remarkable example of frontogenesis near the Alps. Q. $\mathcal{F} . R$. Meteorol. Soc., 117, pp. 125-150

Wallace, J. M. and Hobbs, P. V. (1977) Atmospheric science: an introductory survey. Academic Press, San Diego, xvii $+467 \mathrm{pp}$.

\title{
The Papal front Part 3: Findings from research-type analyses
}

\author{
Hans Volkert ${ }^{1}$ and Reinhold Steinacker ${ }^{2}$ \\ 1 Institut für Physik der Atmosphäre, DLR-Oberpfaffenhofen, Weßling, Germany \\ 2 Institut für Meteorologie und Geophysik, Universität Wien, Vienna, Austria
}

This is the third paper in a series of three that were written following case-study work at the Meteorological Office Summer School on "Orographic Processes in Meteorology" held in July 1993. In Part 1 John Sherwood gave the forecaster's perspective (Sherwood 1995); Part 2 discussed to what extent current operational weather prediction models were able to capture the event (Volkert et al. this issue). We now present some additional data analyses from a research-oriented point of view. Two questions are addressed: (i) how much is known about the synoptic-scale situation in which the Papal front developed? and (ii) how well can its threedimensional structure be inferred after it had developed? At the same time we relate the Papal front's synoptic-scale setting to that of the Great Storm of 1987 (discussed in some depth in this journal by, e.g., Hoskins and Berrisford 1988; HB from now on) and a well sampled Icelandic depression (Shapiro 1985). Furthermore, a comparison of manual and automated frontal analyses at upper levels indicates what could be gained operationally if better resolved upper-air data were available.

Potential vorticity (PV) is used as well as the 
primary variables to depict the synoptic-scale situation, whereas the frontal structure is diagnosed in terms of potential and equivalent potential temperatures. Some general remarks about these derived quantities appear to be appropriate (even if they are now regarded as standard means for synopticians dealing with cyclones and fronts); an explanation of potential and equivalent potential temperatures is given in the appendix of Part 2 (this issue), while potential vorticity is explained in the appendix below.

\section{Synoptic-scale forcing}

Many significant low-level weather events are induced by synoptic-scale disturbance aloft. A concise, easily assimilated view of the uppertropospheric situation is provided by maps of horizontal motion and potential temperature at the tropopause level, here chosen to coincide with the surface PV $=1.5$ pvu. The same approach has been used before, e.g. for an analysis of the Great Storm of October 1987 over southern England (cf. HB, their Fig. 5).

Such maps are given in Fig. 1 every six hours during the period from 0000 to 1800 GMT on 3 May 1987 , i.e. prior to and during the distinct frontogenesis at lower levels just north of the Alps. Most prominent is the U-shaped zone of steep gradient in potential temperature (highlighted by the blackened interval from 305 to $310 \mathrm{~K}$ ), which depicts a distinct upper-level trough only about $10^{\circ}$ wide in longitude (equivalent to some $800 \mathrm{~km}$ ). The trough moved south-eastwards with an estimated speed of 15 to $20 \mathrm{~m} \mathrm{~s}^{-1}$ (some 300 to $400 \mathrm{~km}$ within 6 hours). At all four analysed times, winds of 30 to $40 \mathrm{~m} \mathrm{~s}^{-1}$ circled round the trough. At noon its leading edge lay above the north-western flank of the (model) Alps.

Zonal cross-sections through the trough help to elucidate the three-dimensional structure of the disturbance (Fig. 2). Within the short-wave trough the tropopause is lowered by some $250 \mathrm{mbar}$ to the $500 \mathrm{mbar}$ level. Simultaneously the isentropes ( $\theta=295 \mathrm{~K}$, say) were elevated by some 300 mbar up to about 500 mbar. Slightly asymmetric jet cores (stronger winds to the west) were located at the flanks of the 'tro- popause dip'. Clearly, the synoptic-scale situation, from which the Papal front developed, was of the cold-core type with cyclonic winds aloft as classified in PV terms by Thorpe (1986) and archetypically discussed by Hoskins et al. (1985; cf. their Fig. 15 (a)).

It follows from theoretical arguments (see, e.g., Hoskins et al. 1985, section 4) and practical experience that ascending motion takes place at and below the leading flank of the sloping tropopause. Additional forced ascent occurred at lower levels due to orographic blocking when that feature came above the rim of the Alps (see Fig. 1, 1200 GMT). The combination of both these processes is thought to have ignited the Papal front development. Before turning to the three-dimensional appearance of the Papal front itself, we make two more general points relating to Figs. 1 and 2 .

Hoskins et al. (1985) juxtaposed crosssections through an Icelandic low on 12 April 1983 in their Fig. 9, which were obtained from an analysis provided by the European Centre for Medium-range Weather Forecasts (ECMWF) and direct dropsonde observations made with a research aircraft (see also Shapiro 1985). A comparison with Fig. 2 nicely illustrates: (i) that the spatial resolution of the operational ECMWF analysis has come quite close to that of a research mission some ten years ago, and (ii) that upper-level tropospheric disturbances at the end of the storm track over Europe can be considerably tighter than those related to a mature Icelandic low (width of the 'tropopause dip' less than $700 \mathrm{~km}$ as compared with more than $1100 \mathrm{~km}$ ).

When comparing our case with the situation of the Great Storm over England (HB; their Figs. 4 and 5) we recognise a much more localised anomaly in the tropopause height (compared with the steep tropopause jump from mid-latitude to nearly tropical values) and, thus, a less strong gradient of potential temperature $(25 \mathrm{~K}$ compared with $40 \mathrm{~K}$ over about $250 \mathrm{~km}$ ) on the tropopause (as defined using potential vorticity).

\section{Three-dimensional frontal structures}

In contrast to operational frontal analysis, where usually only a single level (the surface or 


\section{$00 \quad 06$}

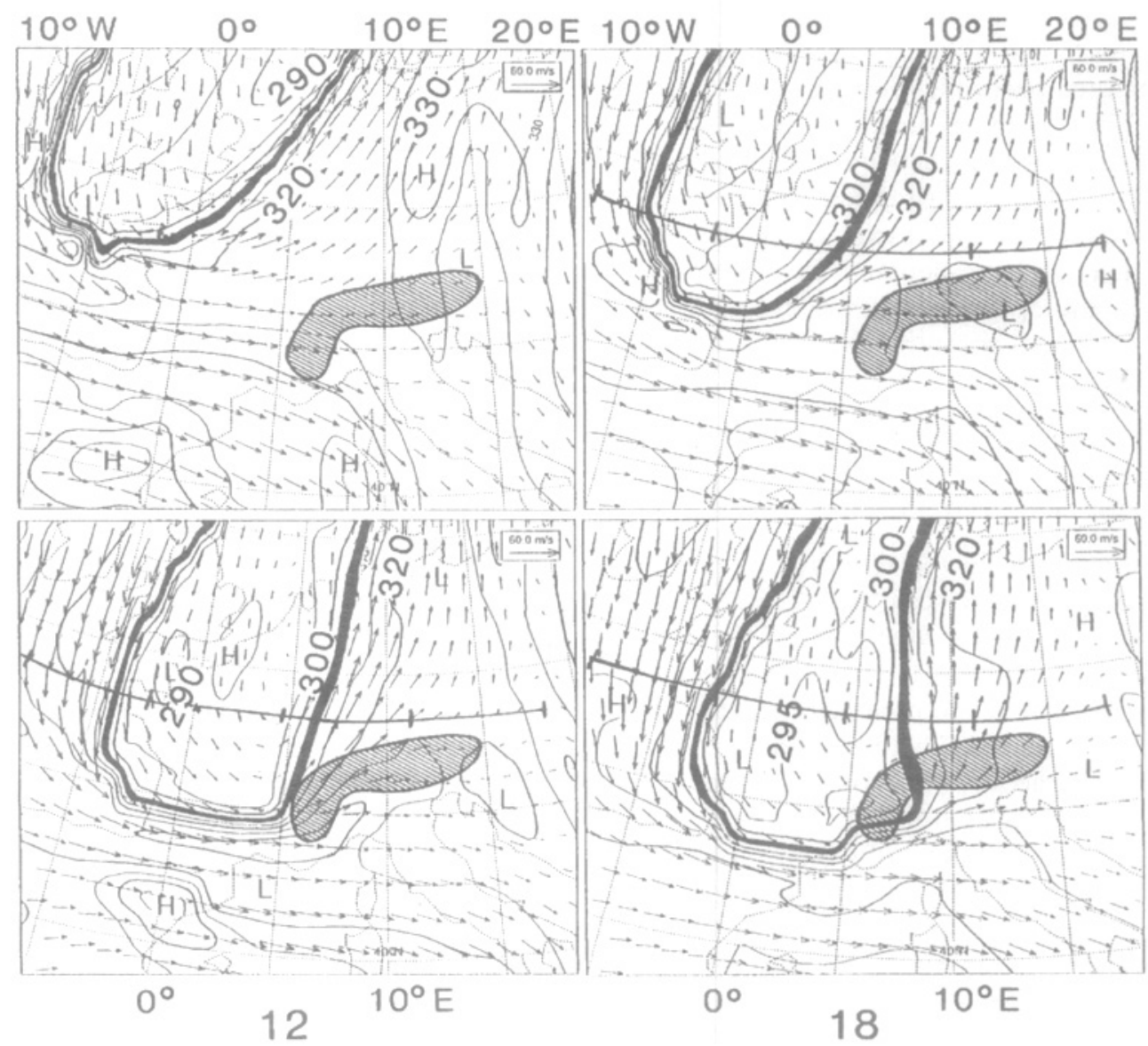

Fig. 1 Potential temperature and wind on the dynamical tropopause (1.5pvu potential vorticity surface; see text for explanation). The data are taken from reanalyses of the ECMWF with $T 213$ spectral resolution and interpolated on to a grid with a spacing between grid points of $1.125^{\circ}$ (wind vectors are displayed at every grid point) at 0000, 0600, 1200 and 1800 GMT on 3 May 1987. Contour increment is $5 \mathrm{~K}$. The interval 305 to $310 \mathrm{~K}$ is blackened. Alpine model heights above $1500 \mathrm{~m}$ are hatched. At 0600,1200 and 1800 GMT the position and tick-marks of the cross-sections in Fig. 2 are indicated.

850 mbar) is considered, a three-dimensional analysis allows us to obtain a more consistent picture of a frontal system and helps us to gain insight into its dynamics, e.g. frontogenesis, frontolysis, interaction between upper-and lower-tropospheric baroclinic zones, change of frontal inclination, formation of secondary frontal structures (see, e.g., Steinacker 1987, 1992).

Due to the dense central European surface network the location of surface fronts is generally not a difficult task. In the Alpine region the numerous mountain stations offer valuable data for the levels up to 700 mbar. These stations are above the low land's boundary layer and give some indication of the state of the atmosphere over the Alps.

The radiosonde network, although fairly dense (mean distance about $250 \mathrm{~km}$ ) compared with other parts of the world, does not really resolve meso- $\beta$-scale ${ }^{\star}$ structures within broad

\footnotetext{
* Meteorological phenomena are often roughly categorised according to their horizontal extent. The medium-scale, or mesoscale, covers spatial scales from $2500 \mathrm{~km}$ down to $2.5 \mathrm{~km}$ with sub-categories meso- $\alpha$, meso- $\beta$ and meso- $\gamma$ for the ranges $2500 \mathrm{~km} \leftrightarrow 250 \leftrightarrow 25 \leftrightarrow 2.5 \mathrm{~km}$, respectively.
} 


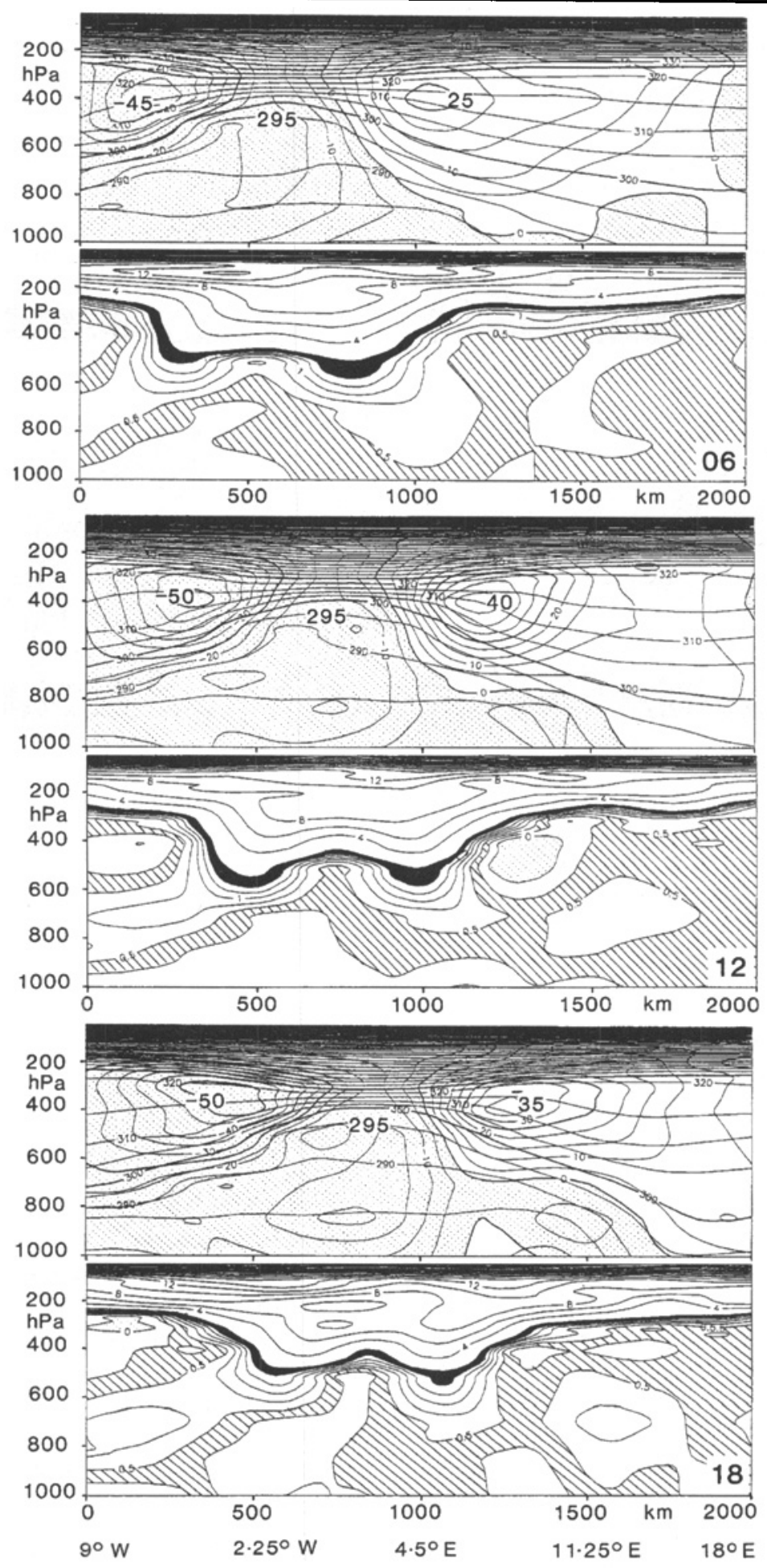

Fig. 2 Cross-sections of potential temperature and meridional wind (upper panels) and potential vorticity (lower panels) along $48.375^{\circ} \mathrm{N}$ through the 0600, 1200 and 1800 GMT ECMWF analyses for 3 May 1987. Contour intervals are 5K, $5 \mathrm{~ms}^{-1}$, and 0.25 pru (2pvu) below (above) the blacked tropopause zone (1.5 to 2.0pvu). The range between 0.25 and 0.5 pvu is hatched; dotted regions contain negative values. (1 hPa $\mathrm{日} 1 \mathrm{mbar}$.) 

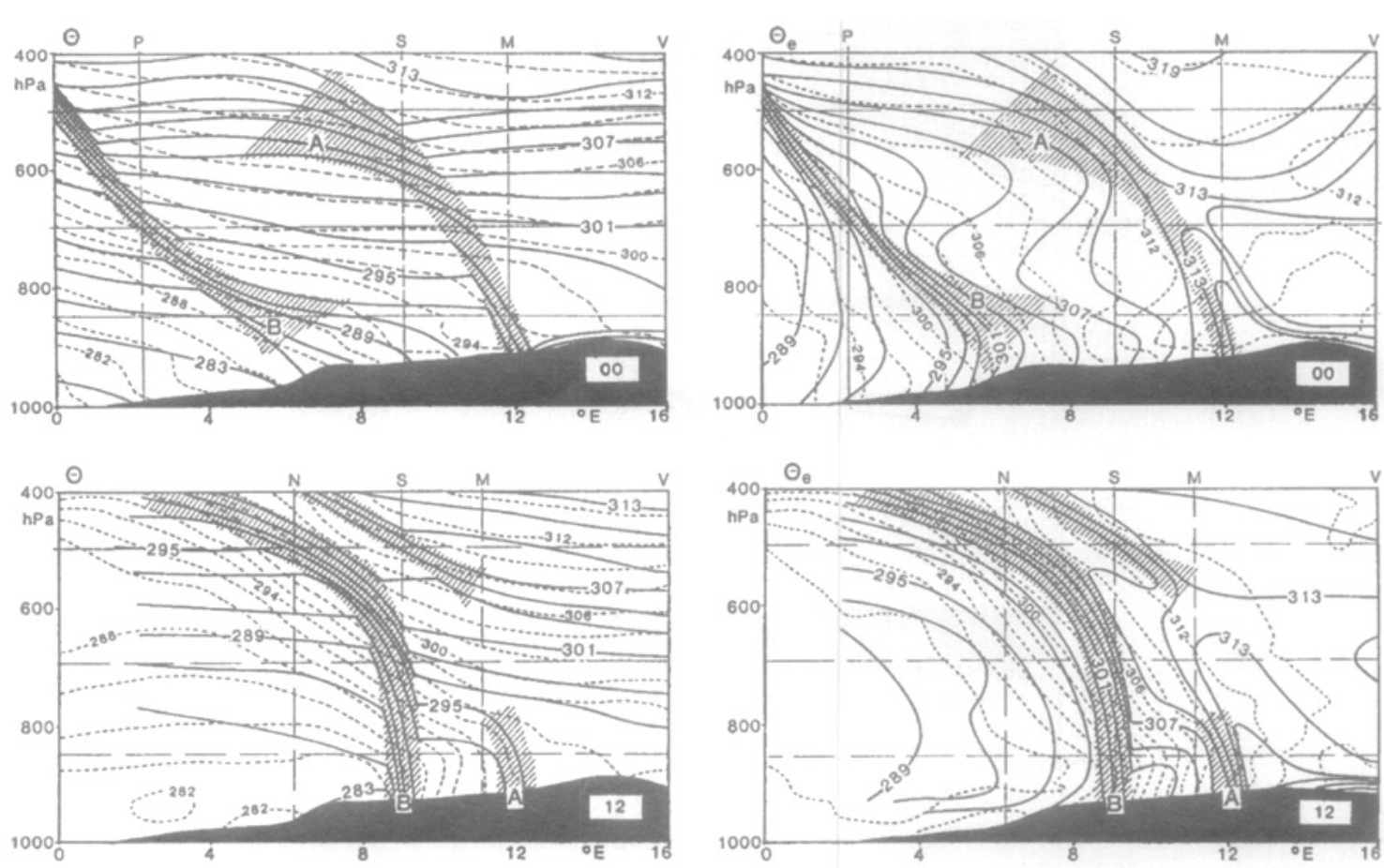

Fig. 3 Mesoscale west-east cross-sections of potential temperature (left) and equivalent potential temperature (right) along $48^{\circ} \mathrm{N}$. Dashed lines are from the ECMWF analyses of $0000 \mathrm{GMT}$ (top) and $1200 \mathrm{GMT}$ (bottom). Full lines are from manual analyses of the upper-air soundings from Paris $(P), \operatorname{Nancy}(N)$, Stuttgart $(S)$, Munich $(M)$, and Vienna (V) blended with manual analyses on the standard pressure levels of 850,700, and 500mbar (thin horizontal lines; see text for details). The hatched regions ' $A$ ' and ' $B$ ' designate two frontal zones as determined from the potential temperature analysis. Contour increment is $2 K$. (1hPa日 Imbar.)

baroclinic zones (regions with large temperature variations). However, when making use of threeor even four-dimensional data consistency, quite narrow frontal zones can be detected throughout the troposphere. Figure 3 shows an example of cross-section analyses of potential and equivalent potential temperature for two times between which the Papal front underwent strong frontogenesis.

The location of the narrow frontal zones (hatched areas in Fig. 3) was first determined using the significant-level radiosonde data. To fill the gaps between the radiosonde stations, information from horizontal analyses on pressure levels was utilised. Assuming that the along-front variability of the meteorological parameters is much smaller than across the front (strong spatial anisotropy), the narrow bands of increased gradient of potential and equivalent potential temperature within the broad baroclinic zone can be located quite accurately. This pressure-level information then has to be substituted into the cross-sections. By that means much sharper structures can be obtained even between adjacent radiosoundings.

In the upper left frame of Fig. 3 isotherms of potential temperature are displayed which were manually analysed as described above. Furthermore, the automated ECMWF analysis is given for 0000 GMT on 3 May 1987. The upper right frame contains the fields of equivalent potential temperature in the same fashion. A first band, 'A', has just reached Munich with its easternmost extension and extended up to 500 mbar above Stuttgart. This translates to a frontal inclination of about 1:50, quite typical for a cold front. A second band, 'B', lies roughly $800 \mathrm{~km}$ to the west of ' $A$ ', especially pronounced at mid- and uppertropospheric levels. This second structure is connected with the sharp inclination of the $1.5 \mathrm{pvu}$ 

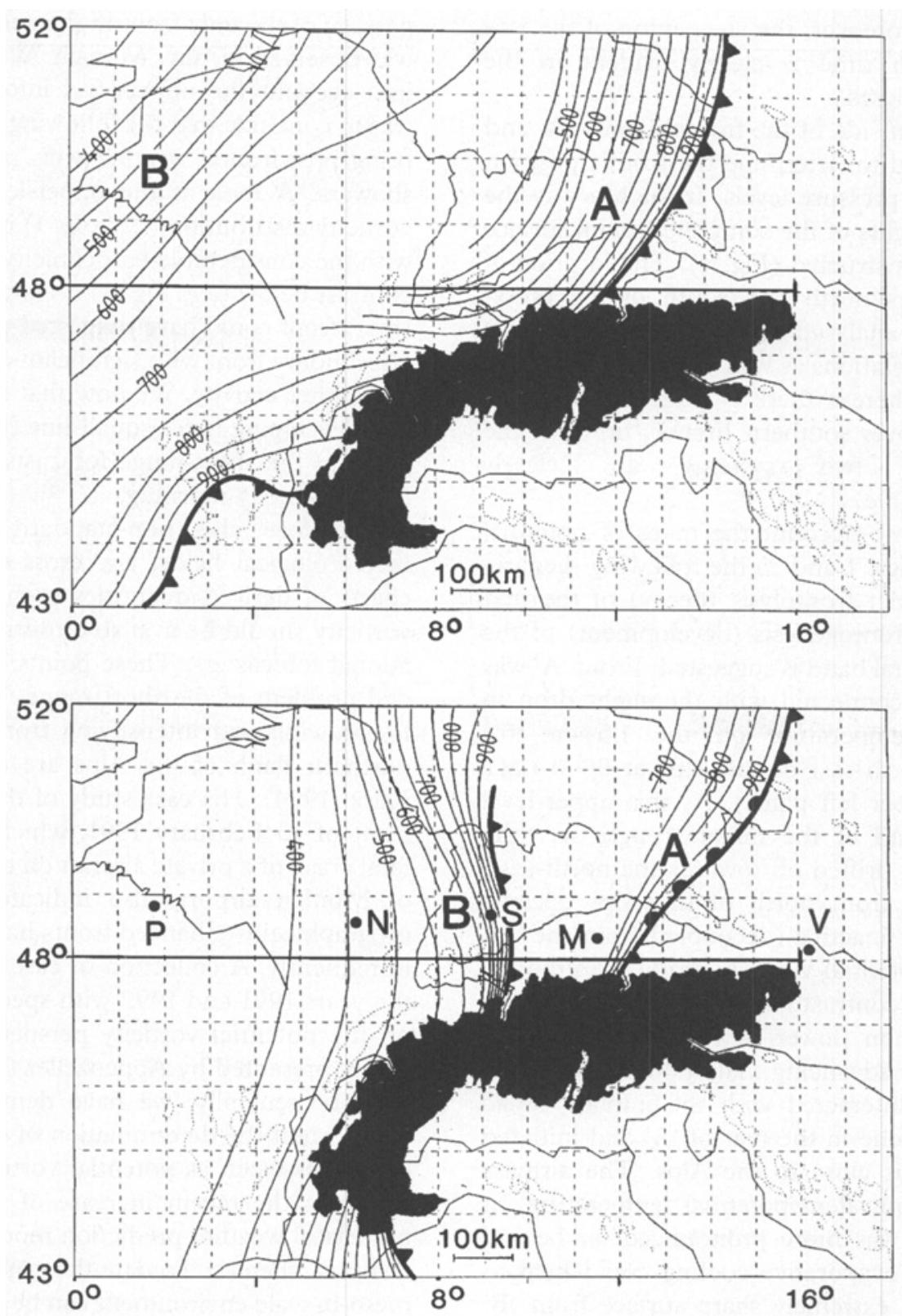

Fig. 4 Pressure height of the leading edge of the frontal zones ' $A$ ' and ' $B$ ' to the north and the west of the Alpine arc for 0000 (top) and $1200 \mathrm{GMT}$ (bottom) on 3 May 1987; contour interval is $50 \mathrm{mbar}$. The frontal positions are manually determined in sections of potential temperature as along $48^{\circ} \mathrm{N}$ (Fig. 3). The locations of the upper-air soundings used for Fig. 3 are also indicated.

tropopause in Fig. 1 (upper left panel). Twelve hours later (lower panels of Fig. 3) the first front had nearly disappeared except within the lowest $2 \mathrm{~km}$, whereas the second had increased its intensity and slope especially at lower levels. A comparison of the continuous and dashed sets of lines reveals that the overall structure of manual and automated analyses is consistent, while the sharpness of the two narrow frontal zones is obtained only through the manual analysis. Slight indications of a double structure are present even in the automated 
analyses. Moreover, the steepening of the isotherms with time is clearly evident in the ECMWF analyses.

The warm side of the frontal bands ' $A$ ' and ' $B$ ' was used to determine the front's position at different pressure levels. In such a way the isobaric heights of the complete frontal surface could be constructed (Fig. 4). The location of the contours north and south of the crosssection was analysed with the aid of additional radiosonde stations as well as Alpine mountain stations. Whereas there is no indication of a split front over southern France, north of the Alps the two systems are clearly distinguishable.

Taking into account the maps of potential vorticity (Figs. 1 and 2 ) the following scenario of the distinct frontolysis (decay) of the first and rapid frontogenesis (development) of the second frontal band is suggested: Front ' $A$ ' was apparently connected with the slight drop in potential temperature on the $1.5 \mathrm{pvu}$ tropopause north-east of the Alps at 0000 GMT (Fig. 1, upper left panel). As this upper-level system ahead of the major trough over the British Isles drifted off towards the north-east, the surface front north of the Alps became dynamically inactive (decoupled from the upper-level potential vorticity gradient) although the airmass contrast remained quite considerable until noon (lower right frame of Fig. 3). The rapidly advancing main potential vorticity maximum interacted with the initially broad baroclinic zone in the rear of 'A' and initiated frontogenesis close to the Alps. The airmass contrast (equivalent potential temperature) at 0000 GMT was more pronounced far behind ' $A$ ' so that evaporative cooling could help to develop the extremely sharp surface front ' $B$ ' (lower left frame of Fig. 3) until 1200 GMT (the Papal front). In addition the blocking of the cold air below crest height was also conducive to the dramatic weather event in the Munich area.

\section{Concluding remarks}

What can be learnt from this case, particularly for practical forecasting? Analysing only the surface (or 850 mbar) chart can be quite misleading. In the early hours of 3 May 1987 the passage of the only front in the surface analysis was observed in, say, Munich. Without taking into account the upper-level information one was to conclude that the following hours would bring post-frontal weather with perhaps some showers. A look at the upper-level potential vorticity distribution (e.g. Fig. 1) in connection with the considerable baroclinicity and airmass contrast below (e.g. Fig. 3) even far behind the (first) front could have suggested the genesis of a secondary front with significant enhancement of weather activity. We note that no indication of a developing fierce squall-line type front was given in the short-range forecasts of that particular Sunday morning.

Therefore also non-standard displays of meteorological fields, e.g. cross-sections, and charts of derived quantities such as potential vorticity should be available routinely to operational forecasters. These points and the general problem of the short-range forecasting of fast-moving and intensifying fronts along the northern flank of the Alps are discussed by Kurz (1994). His case-study of the fierce cold front of 10 February 1991, which caused the fatal crash of a private aircraft on to the runway of Munich airport, also indicates that such orographically enhanced fronts happen not too infrequently. A collection of case-studies from the years 1991 and 1992 with special emphasis on the potential vorticity perspective was recently presented by Appenzeller (1994).

More generally, we have demonstrated to what extent the determination of second-order quantities, such as potential vorticity, benefitted from the recent increase of resolution in numerical weather prediction models and their analysis schemes. To date the synoptic or even meso- $\alpha$-scale environment can be inferred with the accuracy of a research aircraft mission some ten years ago - at least over Europe with its comparatively dense radiosonde network. For the detection of meso- $\beta$-scale structures, however, manual analyses are still indispensable.

Since 1993, operational numerical shortrange forecasts have been made for the Alpine region in Germany and Switzerland with a horizontal grid resolution of $15 \mathrm{~km}$. The new mesoscale model of the Meteorological Office has similar capabilities, but is focused on the British Isles for its routine operations (research- 
type hindcasts of the Papal front case have been presented by Volkert et al. 1991). These tools have the potential to resolve multiple frontal structures, such as occurred on 3 May 1987. The model resolution is, however, more than ten times higher than the typical horizontal distance between upper-air stations. This makes a rigorous evaluation of the model performance a difficult task, especially for levels above the surface. Regular use of manual analyses and a more systematic incorporation of the numerous mountain stations in the Alpine region could help to ameliorate the current state of affairs.

It is among the objectives of a new concerted European effort, the Mesoscale Alpine Programme (see, e.g., Binder and Schär 1995), to employ the meso- $\beta$-scale models mentioned above as research tools to improve our understanding in the field of 'modification of fronts by orography' with special emphasis on the rôle of moisture. So the Papal front may well continue to be a case of high scientific interest.

\section{Acknowledgements}

This study results from a fortunate European co-operation. The Papal front was selected as a case-study for the Summer School when the first author paid an extended visit to the research department of ECMWF. His hosts kindly integrated the case into the reanalyses program, which applies the new T213L31 model system to 'historic' situations. The second author became involved after the Summer School, for which he was invited as lecturer.

Paul Berrisford (University of Reading) made available programs to diagnose potential vorticity and to set up cross-sections. Gertraud Jacob (German Aerospace Research Establishment - DLR) competently finalised the figures. This assistance and the general support of ECMWF, the Meteorological Office, and DLR are gratefully acknowledged.

\section{Appendix: A brief explanation of poten- tial vorticity}

The spinning or vortical nature of synopticscale flow is a daily experience and nicely illustrated by, for example, animated satellite cloud imagery. Vorticity is mathematically defined as the curl of the wind field. So, the vorticity field of a horizontal flow can be imagined as twice the angular velocity that tiny discs would attain within the rotational flow field. Likewise the rotating Earth possesses a planetary vorticity, the relevant magnitude of which varies with geographical latitude. The absolute vorticity of an air parcel equals the sum of the planetary vorticity of its location on Earth plus the relative vorticity due to its motion relative to the Earth. In 1940, Rossby coined the term potential vorticity $(P V)$ for the vorticity which a parcel of air would attain when its stability (vertical gradient of potential temperature) and its latitude were changed to standard values. The varying spin of a skater when stretching his arms or pulling them to the body provides an illustrative analogy for the transformations of observed vorticity from the reservoir of potential vorticity; as with the skater's angular momentum, so PV is conserved when certain criteria are met.

Later on, the term potential vorticity started to be used for a more general and important quantity relating the absolute vorticity and the gradient of potential temperature, which unfortunately does not have the physical dimension of vorticity. An essential feature of PV in this generalised sense is that it is a conserved quantity in adiabatic, frictionless flow just as potential temperature is. For our study it is sufficient to know that PV can be used to define the tropopause in a dynamic way (here: tropopause at $\mathrm{PV}=1.5 \mathrm{pvu} ; 1 \mathrm{pvu}=10^{-6} \mathrm{~m}^{2} \mathrm{~s}^{-1} \mathrm{~K} \mathrm{~kg}^{-1}$ ) with lower (higher) values in the troposphere below (stratosphere above). For more details on this, the historic development, and formulae see $\mathrm{HB}$ and the first chapter of Hoskins et al. (1985).

\section{References}

Appenzeller, C. (1994) Wave developments on surface fronts and stratospheric intrusions. Dissertation No. 10471, ETH, Zürich, $117 \mathrm{pp}$. (can be obtained from LAPETH, CH-8093 Zürich, Switzerland)

Binder, P. and Schär, C. (1995) (Eds.) Mesoscale Alpine Programme - Design Proposal. SMA, Zürich, 63pp. (can be obtained from SMA, CH-8044 Zürich, Switzerland)

Hoskins, B. J. and Berrisford, P. (1988) A potential 
vorticity perspective of the 15-16 October 1987 storm. Weather, 43, pp. 122-129

Hoskins, B. J., McIntyre, M. E. and Robertson, A. W. (1985) On the use and significance of isentropic potential vorticity maps. Q. F. R. Meteorol. Soc., 111, pp. 877-946

Kurz, M. (1994) Die Kaltfront vom 10.2.1991 - Betrachtungen zur Erscheinungsform und zur Vorhersage orographisch beeinflußter Fronten. Meteorol. Z., Neue Folge, 3, pp. 275-287

Shapiro, M. A. (1985) Dropwindsonde observations of an Icelandic low and a Greenland mountain-lee wave. Mon. Wea. Rev., 113, pp. 680-683
Sherwood, J. (1995) The Papal front. Part 1: A forecaster's perspective. Weather, 50, pp. 98-106

Steinacker, R. (1987) Orographie und Fronten. Wetter und Leben, 39, pp. 65-70

- (1992) Dynamical aspects of frontal analysis. Meteorol. Atmos. Phys., 48, pp. 93-103

Thorpe, A. J. (1986) Synoptic scale disturbances with circular symmetry. Mon. Wea. Rev., 114, pp. 1384 1389

Volkert, H., Weickmann, L. and Tafferner, A. (1991) The Papal Front of 3 May 1987: A remarkable example of frontogenesis near the Alps. Q. J. R. Meteorol. Soc., 117, pp. 125-150

\title{
To burn or not to burn
}

\author{
A. R. Webb \\ Department of Meteorology, University of Reading
}

It was Coco Chanel who first popularised the sun-tan, her bronzed limbs inverting its image from the mark of the humble working man to a symbol of the wealthy, leisured and successful. Soon the Victorian ideal of a lady's soft, white skin was tossed away, along with the parasols and bonnets, as fashion, society, and the evereasier means to travel nurtured a generation of heliophiles. After several decades during which the population of sun-darkened skins expanded on the beaches of Greece and Spain, and the ski slopes of Switzerland and France, the longterm consequences of prolonged sun exposure have become evident (Epstein 1983; Elwood et al. 1985; Whelan et al. 1990). They are not pretty.

Most people will have experienced the acute effects of too much sun, a painful reddening of the skin, blistering in severe cases, and the peeling of the upper layers of the skin. This reddening, sunburn or erythema, is caused by ultraviolet (UV) radiation, the shortest wavelengths of radiation to reach the Earth from the Sun. Because of their short wavelengths (high frequencies) UV photons carry more energy than other incident radiation and initiate many biological and chemical reactions (United Nations Environment Programme 1991; Young et al. 1993); erythema is just one commonly experienced and easily observed example.

UV radiation can be split into three wave bands: designated UVA $(315-400 \mathrm{~nm})$, UVB $(280-315 \mathrm{~nm})$ and UVC $(200-280 \mathrm{~nm})$. All UVC from the Sun is absorbed in the upper atmosphere by oxygen and ozone. UVB is also absorbed by ozone, but as wavelength increases the absorption by ozone decreases and an increasing number of photons reach the Earth's surface. This gives the solar spectrum at the ground a characteristic steep 'shoulder' across the UVB waveband (Fig. 1). UVA wavelengths are little affected by ozone and the intensity of UVA radiation is several orders of magnitude greater than that of UVB. During periods of low column-ozone the short-wavelength UVB at the surface is expected to increase while UVA remains unchanged. Observations in Antarctica during the marked spring-time ozone depletion confirm this theory (Booth et al. 1994), and increased UVB with the spectral signature of ozone depletion has also been measured in Ushuaia, southern Argentina (Frederick et al. 1994), and Toronto (Kerr and McElroy 1993) when ozone has been consistently low for a prolonged period. Over most of the globe the variation in surface UV introduced by cloud and 